УдК $82.0+82$ I.I6I.I ББК $83+83.3(2 \mathrm{Poc}=$ Рус $)$
«ЕДИНЫЙ ТЕКСТ»: К ИСТОРИИ

ТЕРМИНА И О РОЛИ ТЕРМИНА

В ИЗУЧЕНИИ ТВОРЧЕСТВА

Ф.М. ДОСТОЕВСКОГО

(C) 2019 г. Т.Г. Магарил-Ильяева

Институт мировой литературы

им. А.М. Горького Российской академии наук, Москва, Россия

Дата поступления статьи: 26 мая 2019 г.

Дата публикации: 25 декабря 2019 г.

DOI: I0.22455/2500-4247-20I9-4-4-10-27

Аннотация: В настоящей статье вводится теоретическое понятие «единого текста» как основы специального подхода к изучению раннего периода творчества Ф.М. Достоевского. При таком подходе произведения обозначенного периода анализируются в своей взаимосвязи, а не как отдельные тексты. В работе демонстрируется, что основанием для подобного объединения произведений может служить наличие в исследуемый период глобальной философской задачи/проблемы, возникающей перед автором и захватывающей его в определенный период его жизни. Под глобальной философской задачей понимается спектр онтологических вопросов, затрагивающих самые глубокие основания мировоззрения автора. Значимость этой задачи оказывается настолько велика, что писатель неизбежно обращается к ней, ищет пути ее решения через создаваемые им в тот период произведения. Крайне важно в процессе исследования выявить авторскую задачу, ее смысловое ядро, тогда все обнаруживаемые в произведениях исследуемого периода мотивы будут «работать» на раскрытие различных аспектов этой задачи, а сформулированная задача будет верификатором того, что выделенный мотив - авторский, а не исследовательская надстройка. В статье рассматривается задача, лежащая в основе всего раннего творчества Ф.М. Достоевского, которую можно сформулировать как поиски путей преодоления косной оболочки мира.

Ключевые слова: понятие «единый текст», произведения Ф.М. Достоевского І840-х гг., тема сердца, мотив, структура текста, авторская задача.

Информация об авторе: Татьяна Георгиевна Магарил-Ильяева - научный сотрудник, Институт мировой литературы им. А.М. Горького Российской академии наук, ул. Поварская, д. 25 а, І2I069 г. Москва, Россия. ORCID ID: о0оо-о0оI-752I-I898 E-mail: svutka@yandex.ru

Для цитирования: Магарил-Ильяева Т.Г. «Единый текст»: к истории термина и о роли термина в изучении творчества Ф.М. Достоевского // Studia Litterarum. 2019. T. 4, № 4. C. IO-27. DOI: IO.22455/2500-4247-2019-4-4-IO-27 


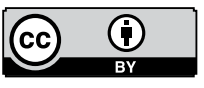

This is an open access article distributed under the Creative Commons Attribution 4.0 International (CC BY 4.0)

\title{
THE SINGLE TEXT: ON THE HISTORY OF THE TERM AND ITS ROLE IN DOSTOEVSKY STUDIES
}

\author{
(C) 20I9. T.G. Magaril-Ilyaeva \\ A.M. Gorky Institute of World Literature \\ of the Russian Academy of Sciences, \\ Moscow, Russia \\ Received: May 26, 2019 \\ Date of publication: December 25, 2019
}

\begin{abstract}
The essay introduces a new term "the single text" as a methodological tool for the study of the early Dostoevsky. This allows me to analyze intersections between different works of the period rather than examine them as individual texts. What justifies the proposed method is the existence of a global philosophical objective/problem that the author is trying to reach/solve in the select period of his life. A global philosophical objective implies a range of ontological questions that relate to the deeper foundations of the author's mindset. This objective is so important that the author recurrently refers to it and is looking for the possible ways to fulfil his goal in different works. It is all the more important to define the author's objective and its meaningful core that unites all the motifs in the works of the select period as they contribute to its implementation. The definition should verify that the featured motif belongs to the author's intention rather than being a whimsical researcher's point of view. The essay therefore examines the underlying goal or objective lying at the core of the early period in the work of Dostoevsky that can be defined as searching for the ways to transcend the inertness of being.
\end{abstract}

Keywords: the concept of the "single text”, Dostoevsky's early period (I84OS), motif, textual structure, author's objective.

Information about the author: Tatyana G. Magaril-Ilyaeva, Researcher, A.M. Gorky Institute of World Literature of the Russian Academy of Sciences, Povarskaya 25 a, I21069

Moscow, Russia. ORCID ID: 000o-00oI-752I-I898

E-mail: svutka@yandex.ru

For citation: Magaril-Ilyaeva T.G. The Single Text: on the History of the Term and its Role in Dostoevsky Studies. Studia Litterarum, 2019, vol. 4, no 4, pp. IO-27. (In Russ.)

DOI: I0.22455/2500-4247-2019-4-4-I0-27 
В филологических исследованиях регулярно используется понятие «единый текст», применяемое для обозначения некоторой группы текстов, причем не обязательно даже созданных одним автором, а, например, принадлежащих одному временному периоду или географической области. Привлечение этого понятия оказывается необходимым, когда исследователь обнаруживает, что полнота смысла (заложенная автором или отражающая некий исторический период) не может быть выявлена через единичный текст. Исследователю оказывается необходимо опереться на ряд текстов, которые в своей взаимосвязи, в своем единстве позволят выявить всю полноту смысла, лежащего в их основе. Неизбежно встает вопрос об определении и обосновании использования понятия «единый текст».

При обосновании использования исследователями данного понятия многие опираются на рассуждения о едином тексте, предложенные Ю.М. Лотманом. Так, например, Т.Б. Фрик в монографии «“Современник” А.С. Пушкина как единый текст» пишет следующее: «В рамках данного диссертационного исследования делается попытка рассмотреть “Современник” как организованную структуру, единый текст, творение которого происходит естественно, в соответствии с основными направлениями развития литературного процесса, объективными условиями существования журнала и эстетическими основами творческого метода его издателя и участвующих в нем авторов. “Современник” не является просто набором или даже последовательностью текстов, отграниченных пределами четырех томов. Пушкинский журнал внутренне организован. Опираясь на лотмановскую концепцию текста, можно сказать, что пушкинский “Современник” представляет 
собой иерархическую систему, которая на синтагматическом уровне превращается в структурное целое» [ІІ, с. 8].

Ю.М. Лотман в работе «Структура художественного текста» рассматривает искусство как одну из форм познания жизни. Окружающий мир находится в постоянном контакте с нами, но мы далеко не всегда способны услышать и понять его. Искусство становится «генератором» тех языков, через которые мы постигаем жизнь и ее «сигналы», произведения искусства оказываются текстами. Язык, по Ю.М. Лотману, - это система знаков, которые сочетаются между собой по определенным правилам, что дает возможность говорить о том, что сама система обладает структурой и иерархией. Лотман подчеркивает важность системности языка, взаимосвязанности всех его элементов. Соответственно, в каждом тексте существует структура, выявить которую и есть задача исследователя, при этом может оказаться, что в обнаруженную структуру входит не один текст, а несколько: «Если мы возьмем большую группу функционально однородных текстов и рассмотрим их как варианты некоего одного инвариантного текста, сняв при этом все “внесистемное” с данной точки зрения, то получим структурное описание языка данной группы текстов. Так построена, например, классическая “Морфология волшебной сказки” В.Я. Проппа, дающая модель этого фольклорного жанра. Мы можем рассмотреть все возможные балеты как один текст...» [7]. Если оказывается возможным, согласно Ю.М. Лотману, выделить общую систему более чем в одном тексте, то об этих текстах можно говорить как об одном или едином тексте. Если мы способны выделить некую общую систему для группы разнородных произведений искусства, то о них также вполне правомерно говорить как о едином тексте.

Каким образом мы можем гарантировать системность, т. е. наличие связи между элементами, если речь идет не об одном тексте, а о нескольких? Ю.М. Лотман в работе, посвященной анализу стихотворения А.С. Пушкина «Зорю бьют...», рассуждает: «Текст представляет собой повествование, и трудности его анализа - в значительной мере трудности работы с нарративным материалом при неразработанности лингвистического аппарата анализа сверхфразовых структур. В этих условиях наибольший опыт изучения повествовательного текста, членения его на сегменты и анализа структуры их соотнесения накоплен теорией кинематографа. Некоторый навык работы по анализу киноленты может оказаться чрезвычайно полез- 
ным при работе с повествовательными словесными текстами» [6, с. I59]. И далее: «Аналогичный принцип наблюдается и в киномонтаже: общая деталь, изобразительная или звуковая, параллелизм поз, одинаковое движение соединяют два монтируемых кадра» [6, с. І6о]. Ю.М. Лотман говорит о необходимости выявления схожих элементов. Такими элементами могут быть созвучия слов или фраз, повторяющиеся описания или смысловые фрагменты. Именно схожие/созвучные элементы говорят о наличии связей между ними, т. е. о наличии системы.

На основании всего вышеизложенного «единым текстом» мы можем называть группу однородных (принадлежащих к одной сфере искусства) или разнородных (принадлежащих к разным видам искусства) произведений искусства (текстов), составные элементы которой возможно включить в единую систему, обладающую упорядоченной, т. е. подчиняющейся особым законам, связью между этими элементами. Связь между элементами, т. е. системность, будет обеспечена наличием схожих элементов. Такое понимание «единого текста» укоренилось в сознании многих исследователей и кажется уже общим местом. Следует отметить, что в данной системе не учитывается личность автора как определяющей основы связи всех элементов.

Однако существует и абсолютно другой подход к пониманию «единого текста», когда в центр системы помещается именно автор как гарант возможности объединения текстов в «единый текст». Очень тонко и точно о первостепенности роли автора говорит И.Б. Роднянская в эссе «Единый текст», посвященном книге о Н.А. Заболоцком: «Развертывание художником своего дара во времени - всегда единый текст. Творящий дух един и в личной судьбе, и в своих, как сказали бы еще недавно, “объективациях”. И это верно вовсе не только в случае романтиков и символистов, специально занимавшихся “жизнетворчеством”, своего рода артистическим исполнением самих себя. Текст един и в случае Пушкина - вопреки его стихотворению “Поэт” [8, с. 36г]. Исследовательница выделяет важный аспект «единого текста», а именно его развертывание во времени. «Единый текст» никогда не был и не мог быть завершенной системой для своего создателя, он был для него через его дар путем поисков и открытий.

«Единый текст» оказывается действительно единым. И это единство задано не исследователем, а верховным законом жизни писателя, где все включено в постоянный процесс созидания. Однако при таком понимании 
«единого текста» утрачивается видимая текстуальная связь группы произведений, которая может не распространяться на все сочинения автора и при этом быть крайне значимой для понимания творческого пути писателя.

Нередко в литературоведении можно встретить, условно говоря, «синтез» двух вышеописанных подходов к пониманию «единого текста», при котором система связанных элементов обусловлена художественным миром автора. Так, С.В. Свиридов в работе «Структура художественного пространства в поэзии В. Высоцкого» отмечает: «Настоящее исследование направлено на изучение одного из аспектов авторского художественного мира, который будет рассматриваться как универсум, состоящий из текстов, и в то же время как единый текст. Эти задачи требуют предварительно остановиться на самих понятиях художественный мир и текст, а также на понятии художественного пространства и его роли в формировании художественного мира» [9].

В данной формулировке «единый текст» оказывается одним из аспектов художественного мира автора. Далее в главе, посвященной теоретическому обоснованию работы, С.В. Свиридов проясняет их соотношение: «С семиотической точки зрения, художественный мир - кодифицированное ядро того единого корпуса текстов, который называют “творчеством автора”. Это область констант, законов, область того “общего языка”, на котором говорят писатель и читатель» [9]. Художественный мир оказывается набором констант, составляющих авторскую модель мира, т. е. языком автора, проявляющимся посредством текстов. С.В. Свиридов справедливо ставит вопрос о том, чем обеспечено наличие констант (схожих элементов) в текстах, не волей ли исследователя. Исследователь приходит к выводу: «Логичнее предположить, что автор обладает некими имплицитными образцами творчества, паттернами, творческими формами, по которым создает конкретные произведения и образы» [9].

Примечательна предложенная С.В. Свиридовым причина, по которой следует изучать художественный мир автора: «Общепризнанно, что анализ художественного мира поэта необходим для познания закономерностей его творчества» [9]. В рассуждениях исследователя обнаруживается некоторая закольцованность: мы изучаем систему элементов в текстах, чтобы познать художественный мир автора, чтобы затем выявить закономерности его творчества, которые очевидно проявляются в текстах. Этот круг 
оказывается чем-то противоположным герменевтическому кругу, при движении по которому мы через части текста познаем его целое, а через целое текста познаем части, приближаясь тем самым к его сути. В данном же случае мы как будто бесконечно ходим по кругу, рассматривая части, скользим по поверхности, не уходя вглубь.

Описав вкратце возможные подходы к пониманию «единого текста», рассмотрим подробнее, как это понятие применяется в достоевистике. Отметим, что в данной статье мы обращаемся к работам тех исследователей, кто непосредственно использует понятие «единый текст» в качестве базы для исследования группы произведений Ф.М. Достоевского.

В.И. Габдуллина в диссертационном исследовании «Евангельская притча в авторском дискурсе Ф.М. Достоевского» объединяет все творчество писателя в единый текст: «Авторская концепция, отражением которой является совокупность произведений Достоевского, реализуется в авторском дискурсе как “синтезе художественной и поэтической идеи” (Ф.М. Достоевский), репрезентирующем идеологические, эстетические и духовно-нравственные установки писателя различными способами, в том числе и через систему кодов и сквозных мотивов, организующих биографию и творчество писателя в единый текст» [I].

Исследовательница полагает, что на «авторскую стратегию творчества» Достоевского оказали значительное влияние библейские притчи. В.И. Габдуллина выделяет в притчах центральные мотивы, которые, по ее мнению, проходят через все творчество Достоевского. На основе выявления в произведениях писателя этого общего притчевого мотива все тексты объединяются в один текст: «В письмах и публицистике, а также в нарративной структуре произведений Достоевского (как ранних, так и принадлежащих к “послекаторжному” периоду творчества), обнаружен мотивный комплекс, восходящий к сюжету притчи о блудном сыне, что позволяет рассматривать мотив блудного сына как сквозной, объединяющий все творчество писателя в единый текст» [I].

В ходе анализа произведений Достоевского исследовательница обнаруживает трансформацию отношения писателя к притче о блудном сыне. Если, по мнению В.И. Габдуллиной, в раннем творчестве этот мотив скорее осмеивается писателем, то позднее ситуация кардинально меняется. При бесспорности наличия сквозного мотива о блудном сыне в творчестве 
Достоевского встает вопрос о правомерности объединения текстов на его основе в «единый текст». Как показала исследовательница, один и тот же мотив выполняет разные функции в различные периоды творчества, т. е., очевидно, меняется задача, которую ставит перед собой автор, используя этот мотив при создании произведения.

Одна из глав монографии О.А. Ковалева «Нарративные стратегии в творчестве Ф.М. Достоевского» носит название «Творчество Ф.М. Достоевского как единый текст». В этой главе автор говорит о так называемых «формулах», которыми насыщены произведения Ф.М. Достоевского. Под формулами автор понимает повторяющиеся фабулы, сюжетные ходы, мотивы: «По мнению Кавелти, имеет смысл говорить о формульной литературе как особом виде литературного творчества, для которого характерно оживление стереотипа без выхода за границы формулы» [4, с. 70]. Иными словами, в основе литературы лежат некие матрицы, которые повторяются от эпохи к эпохе, от произведения к произведению, литература оказывается не изобретением нового или отражением насущной действительности, а результатом наложения «индивидуально-авторского» на существующую матрицу.

По мнению О.А. Ковалева, «Достоевскому в определенной степени было свойственно формульное мышление - воспроизведение готовых сюжетных шаблонов. Отдельные элементы сюжетной структуры его произведений воспринимаются как вторичные именно потому, что воспроизводят некоторые литературные паттерны. Одновременно эти литературные формулы проецируются на те или иные факты, ситуации из жизни писателя. В результате художественные произведения Достоевского представляют собой семиотическую систему, одной своей стороной обращенную к литературе, а другой - к биографии» [4, с. 72]. Здесь можно увидеть один из вариантов совмещения описанных выше подходов к понятию «единого текста». Самому понятию «единый текст» О.А. Ковалев не дает определения, но, как и В.И. Габдуллина, старается выделить мотивы/формулы, проходящие через все творчество писателя, объединяя его в единое сообщение. Например, он выделяет такие мотивы, как «утрата всего» и «чувство вины». О.А. Ковалев приводит варианты сквозных мотивов, предложенные другими исследователями: В.Г. Одинков рассмотрел эволюцию образов «подпольного» и «мечтателя» как «общую покрывающую точку» системы образов писателя; 
И.Л. Волгин анализирует творчество Достоевского как единое текстовое пространство, неизменным сюжетом которого является Россия; Н.Н. Редько говорит о стержневом сюжете развития личности - от пробуждения самосознания к высшему развитию личности.

В «единый текст» объединяется не только весь корпус текстов Достоевского, но и отдельные группы произведений. Традиционно такое разделение совпадает с членением жизненного пути Достоевского на докаторжный, каторжный и послекаторжный периоды. Примечательна работа А.Ф. Седова «Достоевский и текст (проблема текста с точки зрения поэтики повествования в повестях и романах Ф.М. Достоевского 60-70-х годов)», в которой он объединяет произведения I860-I870-х гг. в «единый текст» на основании выявления сквозного мотива, но в то же время формулирует проблематичность подобного подхода.

А.Ф. Седов выбрал довольно необычную для современной науки форму презентации своего исследования - диалог. Так, один из участников диалога утверждает, что произведения Достоевского, созданные в I860-I870-х гг., можно объединить в некое «"надтекстовое единство”, смысловое целое особого рода». Оппонент разумно возражает: зачем ограничиваться одним периодом? - можно все творчество воспринимать как единый текст - и приводит примеры именно такого взгляда на творческий путь писателя. Однако первый участник диалога предлагает сводить произведения данного периода в единство на основании обнаруживаемого в них образа Хрустального дворца (здание как символ прекрасного грядущего). Автор показывает, как этот мотив проявляется в разных произведениях, и отмечает: «Трудность применения сравнительного метода по отношению к творчеству Достоевского состоит не только в том, что писатель создает комплексы идей из противоречивых элементов. В ряде случаев исследователь словно бы тонет в параллелях, а смысл сопоставления в каждом случае определить достаточно сложно, зачастую эти реконструкции следует изначально представлять как гипотетические <...>. Но при всех различиях идейно-нравственная маркировка остается сходной: некое опасливое неприятие этого здания будущего, построенного по законам одного лишь Разума. И одна из снижающих интерпретаций “хрустального дворца” “муравейник” - представлена ведь и в “Записках из подполья”, и в “Братьях Карамазовых”, разве не так?»[го]. А.Ф. Седов понимает уязвимость 
подхода к объединению ряда произведений в «единый текст» на основе одного мотива, так как в обилии схожих элементов нет точного верификатора, который бы подтвердил, что все множество элементов соотносится с выбранным мотивом.

А.Н. Кошечко в диссертационной работе «Формы экзистенциального сознания в творчестве Ф.М. Достоевского» вводит понятие «каторжного текста»: «Синхронизировать и парадигматически обозначить весь спектр размышлений писателя о каторге возможно только в аспекте диахронического анализа, соединив в единый текст сознания все свидетельства разных этапов его жизни. Все вместе они образуют своеобразный “каторжный текст” Достоевского, идейной доминантой которого является мысль о “перерождении убеждений”. Ситуация изгнания, ощущение тотальной оторванности от родных, духовной и литературной жизни активизирует рефлексивные механизмы сознания Достоевского. Не имея возможности устраниться от происходящего вокруг, он ставит перед собой новую экзистенциальную задачу - отыскать смысл и высшие мотивации существования, осознать свое прошлое, не преувеличивая и не искажая его, сохранить себя и свое достоинство» [5]. Здесь под единым каторжным текстом понимается не группа произведений, а совокупность размышлений, осознаний писателя, соотносящихся с пережитым им опытом каторги.

На данный момент в достоевистике нет теоретически обоснованного понятия «единый текст», хотя оно и продолжает применяться. Многие исследователи полагают в качестве основания для объединения ряда произведений в «единый текст» наличие в них общего мотива, однако такой подход видится проблематичным. Как было показано выше, один и тот же мотив в каждый период творчества писателя может осмысляться по-новому, следовательно, выполнять разные функции в произведениях. Помимо этого, выявление единого мотива может вызвать затруднения, как отмечал А.Ф. Седов, при наличии обилия схожих элементов текста нет достаточных оснований полагать, что все они представляют собой некое единство, составляющее авторский мотив.

Что же может служить действительно годным основанием для объединения группы произведений в «единый текст»? Таким основанием, по нашему мнению (опираясь на размышления и высказывания Т.А. Касаткиной), может служить наличие глобальной философской задачи/проблемы, 
возникающей перед автором и захватывающей его в определенный период его жизни. Под глобальной философской задачей в данном случае понимается спектр онтологических вопросов, затрагивающих самые глубокие основания мировоззрения автора.

Писатель неизбежно обращается к этой философской задаче, ищет пути ее решения в первую очередь через создаваемые им в тот период произведения. По каким-то причинам для писателя оказывается важно (или просто невозможно иначе) рассмотреть аспекты стоящей перед ним проблемы через ряд завершенных историй, а не фокусировать весь комплекс вопросов, связанных с поставленной задачей, в одном произведении (большом романе, например). Завершая историю, но не закрывая задачу, писатель получает возможность через полученный опыт (проживание от начала до конца созданной им истории, получение обратной читательской связи) создать следующую историю, уже будучи немного другим человеком, т. е. сместить свой угол зрения, что гораздо труднее сделать, все еще находясь внутри создаваемой истории. Зачастую получается, что некое решение, найденное в одном произведении, становится проблемной точкой для другого. Писатель прощупывает, проясняет для самого себя пути решения проблемы, стоящей перед ним в жизни. Он как будто проживает ее снова, но по-разному в каждом следующем произведении.

Говорить о завершении «единого текста» можно тогда, когда меняется либо задача, поставленная автором, либо авторский взгляд на нее или средства ее решения. То есть автор, пройдя определенный путь, найдя средства решения поставленной задачи и получив опыт, может обнаружить, что те изменения, которые произошли лично с ним в результате его поисков, поместили его совсем в иную точку, нежели ту, в которой он находился, первый раз осознавая свою задачу. Это новое открытие себя может показать писателю, что в своем нынешнем положении он бы сформулировал изначальную задачу совсем иным образом, на другом уровне понимания своих глобальных целей в жизни. Рассматриваемая, таким образом, уже на другом уровне задача несводима к своему первоначальному смысловому ядру, перед нами оказывается на самом деле новая проблема, требующая абсолютно других средств для своего разрешения. Безусловно, возможна ситуация, когда автор решает в принципе отказаться от поставленной проблемы и кардинально меняет вектор своих интересов. 
Для исследователя крайне важно выявить авторскую задачу, ее смысловое ядро, тогда все обнаруживаемые в произведениях исследуемого периода мотивы будут «работать» на раскрытие различных аспектов этой задачи, а сформулированная задача будет верификатором того, что выделенный мотив - авторский, а не исследовательская надстройка. Обнаруживаемые в тексте повторяющиеся слова/словосочетания или сюжетные ходы, за которыми встает один и тот же образ, соединяются в мотив. Если в основе исследуемого периода находится авторская задача, то все образы, составляющие обнаруженные мотивы, будут отражать решаемую автором задачу и представлять один из аспектов или вариантов ее решения.

Конфликтность мотивов - обнаружение противоречащих друг другу по смыслу мотивов - будет сигналом того, что либо мы неверно выявили смысловую линию мотивов, либо не дошли до их истинного смысла, снимающего противоречия между ними. Если же исследователь при объединении ряда произведений в «единый текст» опирается на один мотив или даже несколько, то в отсутствии понимания общей задачи, он не может удостовериться, что выбранные им мотивы - не просто набор схожих сюжетных ситуаций, а заложенные автором значимые линии, раскрывающие смысловое целое произведений.

Решаемая автором задача крайне редко бывает выражена дискурсивно, исследователю приходится восстанавливать ее через единый художественный текст, границы которого не заданы, а выясняются опытным путем в процессе анализа произведений. Исследователь сталкивается с проблемой: с одной стороны, он должен представлять себе глобальную авторскую задачу, которая будет детектором рассматриваемых им мотивов, а с другой стороны, он может прояснить для себя эту задачу только через тщательный анализ художественных элементов, в том числе и мотивов. Это и есть движение по герменевтическому кругу, но не в границах одного произведения, а нескольких, точное количество которых по ходу движения постоянно уточняется.

Чтобы проиллюстрировать наши теоретические рассуждения о понятии «единого текста», обратимся к произведениям Ф.М. Достоевского I840-х гг. Центральную мысль практически всех ранних текстов Достоевского можно сформулировать как поиски пути преодоления косной оболочки мира. Эта задача будет лежать в основе всего художественного творчества 
I840-x гг., но с наибольшей очевидностью она будет выражена в письмах будущего писателя к брату.

Будущий писатель в возрасте I7 лет формулирует свое ощущение действительности следующим образом: «Но видеть одну жесткую оболочку, под которой томится вселенная, знать, что одного взрыва воли достаточно разбить ее и слиться с вечностию, знать и быть как последнее из созданий...» [2, т. 28, с. 50]. Спустя три месяца: «Я ношусь в какой-то холодной, полярной атмосфере, куда не заползал луч солнечный...» [2, т. 28, с. 50]. Достоевский описывает мир, закрытый от солнца, изолированный от общего бытия жесткой оболочкой. Находиться внутри этого мира - то же, что «томиться» в тюрьме или жить на северном полюсе, где вечная ночь и все сковано льдом, жесткой оболочкой.

За описанным ощущением стоит зрелое мировоззрение философа. «Одно только состоянье и дано в удел человеку: атмосфера души его состоит из слиянья неба с землею; какое же противузаконное дитя человек; закон духовной природы нарушен... Мне кажется, что мир наш - чистилище духов небесных, отуманенных грешною мыслию. Мне кажется, мир принял значенье отрицательное и из высокой, изящной духовности вышла сатира. Попадись в эту картину лицо, не разделяющее ни эффекта, ни мысли с целым, словом, совсем постороннее лицо... что ж выйдет? Картина испорчена и существовать не может!» [2, т. 28, с. 50]. Достоевский в приведенном отрывке говорит о совмещении в душе человека двух частей: земной и небесной; причем совмещение это противозаконно - оно нарушило «закон духовной природы». До наличествующего «отрицательного» состояния мира, в котором есть человек, была «высокая, изящная духовность» и «духи небесные». По каким-то причинам дух «отуманился грешной мыслью» соединился с земной составляющей и оказался в мире, скованном косной оболочкой, т. е. отделенном от «высокой духовности».

В этом описании устройства мира звучит продуманная философская позиция, мы не будем сейчас пытаться установить возможные источники этой философии. Однако важно понимать, что образы, созданные писателем в этой картине, - это образы, которыми пользовались мыслители, чьи интересы сосредоточивались на духовной стороне жизни, можно сказать, что это их общий язык. В приведенной цитате исследователями отмечались отголоски романтической, гностической или мистической литературы. 
В России начала XIX в. происходит небывалый всплеск интереса к подобной литературе, распространение которой было одной из форм деятельности масонов. Волна духовного, сверхчувственного постижения мира набирает свою мощь по всей Европе именно как естественное противодействие захвату мира рациональными способами взаимодействия с ним, веку Просвещения. Возникает оппозиция двух способов познания мира: через разум и через сердце. Данное противостояние оказывается темой размышлений и молодого Достоевского: «Познать природу, душу, Бога, любовь... Это познается сердцем, а не умом <...> Ум - способность материальная... душа же, или дух, живет мыслию, которую нашептывает ей сердце... Мысль зарождается в душе. Ум - орудие, машина, движимая огнем душевным... Притом (2-я статья) ум человека, увлекшись в область знаний, действует независимо от чувства, след<овательно>, от сердиа. Ежели же цель познания будет любовь и природа, тут открывается чистое поле сердиу... Не стану с тобой спорить, но скажу, что не согласен в мненье о поэзии и философии... Философию не надо полагать простой математической задачей, где неизвестное - природа <...> чтобы вывести верный результат из этой разнообразной кучи, надобно подвесть его под математическую формулу.

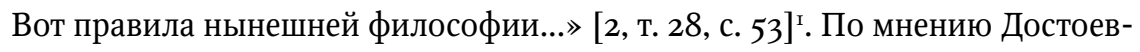
ского, ум - часть материального мира, душа или дух живет через сердце. Люди, являясь частью материи («прах»), могут познавать истинные сущности («душу, любовь, Бога») сердцем. С помощью разума доступны только математические формулы, которые далеки от истинного знания. Сердце для Достоевского оказывается тем самым органом, через который возможно истинное познание как соприкосновение с миром. Именно через такое познание-сопричастие возможно преодоление косности материи.

Большинство героев ранних произведений Достоевского в начале своих историй находятся в ситуации скованности, отгороженности от мира. Ордынов - «отрешившийся от света» [2, т. 2, с. 265], мечтатель «селится $<$...> большею частию где-нибудь в неприступном углу, как будто таится в нем даже от дневного света, и уж если заберется к себе, то так и прирастет к своему углу... [2, т. 2, с. II2], Ползунков, которого никогда не принимают за своего, или маленький герой, которому буквально нигде не находит-

I B данном издании авторское подчеркивание заменено на курсив. 
ся место. То есть точка, в которой мы знакомимся с героями, - это точка невозможности для героев соприкоснуться с миром и занять в нем свое полноправное место. Но с каждым героем в ходе повествования происходит что-то кардинально меняющее ситуацию изоляции, причем не обязательно в лучшую сторону. Это что-то можно обозначить как максимальное раскрытие и включенность сердца, т. е. чувств, за счет чего и происходит соприкосновение с миром. Собственно, эти разнообразные попытки героев пробиться через косную оболочку, отделяющую их от мира, и есть попытка самого Достоевского разрешить стоящую перед ним задачу.

Момент, в который кардинально меняется жизнь героев, - это момент раскрытия сердца. Тема сердца проходит через все ранние тексты Достоевского. Так, столь, казалось бы, опустившийся и потерянный человек, как главный герой рассказа «Ползунков», оказывается обладателем живого сердца, о чем неоднократно нам напоминает автор: «Само собою разумеется, что очерстветь и заподличаться вконец он не мог никогда. Сердце его было слишком подвижно, горячо!» [2, т. 2, с. 6]; «Ваше очерств... не скажу очерствелое, - заблудшее сердце...» [2, т. 2, с. Іо]. Именно это качество позволяет Ползункову прорваться за пределы горизонтального материального мира и разглядеть высший путь человека.

В тексте рассказа фигурирует дата первого апреля. Всеми героями она опознается как день смеха, и только Ползунков опознает в ней день памяти Марии Египетской («...вы, знаете, завтра... Марии Египетские-с...» [2, т. 2, с. 9]). История Марии Египетской - это история раскаявшейся блудницы. Для нас наиболее важен момент ее жизни, когда она, еще будучи грешницей, решила войти в храм, но какая-то сила ее не пустила туда. Она не смогла преодолеть косную оболочку мира, закрывающую его от божественного света. Покаявшись, Мария вошла в храм, после чего отправилась в пустыню, где и провела всю свою жизнь. Ползунков способен видеть эту историю благодаря своему живому сердцу, а значит, пусть и в потенции, путь преодоления косной оболочки мира для него открыт.

Совсем иная ситуация у Васи, героя рассказа с говорящим названием «Слабое сердце». Главный герой оказывается обладателем слабого сердца и сходит с ума, т. е. окончательно замыкается от мира в собственном безумии. Вася не умеет познавать мир сердцем, не умеет общаться с ним через сердце, он спрашивает Аркадия: «...я давно хотел спросить тебя: как это ты 
так хорошо меня знаешь?» [2, т. 2, с. 39], на что друг отвечает: «Если бы ты знал, Вася, до какой степени я люблю тебя, так ты бы не спросил этого, да!» [2, т. 2, с. 39]. Достоевский показывает здесь свое понимание сердца как органа познания-сопричастия: мы по-настоящему можем познать другого, только полюбив его всем сердцем. А все выводы, сделанные благодаря рациональным построениям, не заставят другого сказать: «Как хорошо ты меня знаешь». Так как у Васи не получается осуществить общение с миром через сердце, он оказывается неспособным расплатиться за счастье, посланное ему (внимание начальства, чудесная невеста, верный друг), из-за чего и сходит с ума. Точнее, он уверен, что за счастье надо платить, а это позиция материального мира, где только и возможны отношения «ты - мне, я - тебе». Отношения через сердце основаны на изобильной любви, не требующей платы. Так, Вася сам говорит о своем сердце: «Сердце... во мне было черство... Слушай, как это случилось, что я никому-то, никому я не сделал добра на свете, потому что сделать не мог...» [2, т. 2, с. 39].

Тему живого сердца как органа, позволяющего преодолеть косность материи, можно найти практически во всех ранних текстах Достоевского. Но только о «Маленьком герое» можно с уверенностью сказать, что ему это удалось. В начале своей истории он постоянно оказывается лишним ему не находится места ни в театре, ни на общей прогулке. Доведенный до отчаянья мальчик совершает небывалый поступок - вскакивает на дикого коня Танкреда и укрощает его. Этот момент маленький герой вспоминает как возвышение своего духа: «...я вдруг теперь возмутился всем воскресшим духом моим...» [2, т. 2, с. 285]. После такого поступка его положение кардинально меняется, маленькому герою открывается мир, но и он через сердце открывается миру: «Я закрыл руками лицо и, весь трепеща, как былинка, невозбранно отдался первому сознанию и откровению сердца, первому, еще неясному прозрению природы моей... Первое детство мое кончилось с этим мгновением» [2, т. 2, с. 295].

Достоевский ищет пути преодоления косной оболочки мира вместе со своими героями. В каждом произведении поставленная автором задача раскрывается под новым углом, но именно ее целостное понимание дает возможность увидеть настоящий масштаб ранних произведений писателя.

Таким образом, под «единым текстом» понимается группа произведений, в основе которых лежит глобальная философская задача, решаемая 
автором в период создания этих произведений. Выявление и формулировка этой задачи становятся принципиально важными для адекватной интерпретации всех произведений, входящих в исследуемый период. Анализ отдельных текстов приоткрывает доступ лишь к обособленным аспектам поставленной задачи, что может привести к искажению ее смысла.

\section{Список литературы}

I Габдуллина В.И. Евангельская притча в авторском дискурсе Ф.М. Достоевского: дис. ... д-ра филол. наук. Томск, 2009. 388 с. URL: http://www.dslib.net/russkajaliteratura/evangelskaja-pritcha-v-avtorskom-diskurse-f-m-dostoevskogo.html (дата обращения: 26.05.2019).

2 Достоевский Ф.М. Полн. собр. соч.: в 30 т. Л.: Наука, 1972-1990.

3 Касаткина Т.А. О субъект-субъектном методе чтения // Новый мир. 20I7. № I. URL: http://www.zh-zal.ru/novyi_mi/20I7/I/o-subekt-subektnom-metode-chteniya. html (дата обращения: 26.05.2019).

4 Ковалев О.А. Творчество Ф.М. Достоевского как единый текст // Нарративные стратегии в творчестве Ф.М. Достоевского. Барнаул: Изд-во Алт. ун-та, 201 I. C. $70-74$.

5 Кошечко А.Н. Формы экзистенциального сознания в творчестве Ф.М. Достоевского: дис. .... д-ра филол. наук. Томск, 20I4. 477 с. URL: http://www.dslib.net/russkajaliteratura/formy-jekzistencialnogo-soznanija-v-tvorchestve-f-m-dostoevskogo.html (дата обращения: 26.05.2019).

6 Лотман Ю.М. Анализ поэтического текста. Л.: Просвещение, г972. 272 с.

7 Лотман Ю.М. Структура художественного текста // Лотман Ю.М. Об искусстве. СПб.: Искусство - СПБ, І998. С. I4-285. URL: https://www.gumer.info/bibliotek Buks/Literat/Lotman/_Index.php (дата обращения 26.05.2019).

8 Роднянская И.Б. Единый текст // Движение литературы. М.: Знак: Языки славянских культур, 2006. Т. г. С. 36I-376.

9 Свиридов С.В. Структура художественного пространства в поэзии В. Высоцкого. URL: http://vysotskiy-lit.ru/vysotskiy/kritika/sviridov-struktura-prostranstva/index. htm (дата обращения: 26.05.20I9).

Iо Седов А.Ф. Достоевский и текст (проблема текста с точки зрения поэтики повествования в повестях и романах Ф.М. Достоевского 6о-70-х годов). Балашов, 2002. URL: https://refdb.ru/look/2683III.html (дата обращения: 26.05.20I9). Фрик Т.Б. «Современник» А.С. Пушкина как единый текст. Томск: Изд-во Томского политехнического ун-та, 2009. 192 с. 


\section{References}

I Gabdullina V. I. Evangel'skaia pritcha v avtorskom diskurse F.M. Dostoevskogo [The gospel parable in the author's discourse by F.M. Dostoevsky: PhD thesis]. Tomsk, 2009. 388 p. Available at: http://www.dslib.net/russkaja-literatura/evangelskaja-pritcha-vavtorskom-diskurse-f-m-dostoevskogo.html (Accessed 26 May 20I9). (In Russ.)

2 Dostoevskii F.M. Polnoe sobranie sochinenii: $v$ zo $t$. [Complete works: in 30 vols.] Leningrad, Nauka Publ., 1972-1990. (In Russ.)

3 Kasatkina T.A. O sub"ekt-sub"ektnom metode chteniia [On subject-subjective method of reading]. Novyi mir, 20I7, no I. Available at: http://www.zh-zal.ru/novyi_mi/20I7/I/ o-subekt-subektnom-metode-chteniya.html (Accessed 26 May 20I9). (In Russ.)

4 Kovalev O.A. Tvorchestvo F.M. Dostoevskogo kak edinyi tekst [Creativity F.M. Dostoevsky as a single text]. Narrativnye strategii v tvorchestve F.M. Dostoevskogo [Narrative strategies in the works of F.M. Dostoevsky]. Barnaul, Izd-vo Alt. un-ta Publ., 20II, pp. 70-74. (In Russ.)

5 Koshechko A.N. Formy ekzistentsial'nogo soznaniia v tvorchestve F.M. Dostoevskogo [Forms of existential consciousness in the works of F.M. Dostoevsky: PhD thesis]. Tomsk, 20I4. 477 p. Available at: http://www.dslib.net/russkaja-literatura/formyjekzistencialnogo-soznanija-v-tvorchestve-f-m-dostoevskogo.html (Accessed 26 May 20I9). (In Russ.)

6 Lotman Iu.M. Analiz poeticheskogo teksta [The analysis of poetic text]. Leningrad, Prosveshchenie Publ., I972. 272 p.

Lotman Iu.M. Struktura khudozhestvennogo teksta [The structure of the artistic text]. Lotman Iu.M. Ob iskusstve [About art]. St. Petersburg, Iskusstvo - SPB Publ., I998, pp. I4-285. Available at: https://www.gumer.info/bibliotek_Buks/Literat/Lotman/_ Index.php (Accessed 26 May 20I9). (In Russ.) Rodnianskaia I.B. Edinyi tekst [The single text]. Dvizhenie literatury [Movement of literature]. Moscow, Znak: Iazyki slavianskikh kul'tur Publ., 2006. Vol. I, pp. 36I-376. Sviridov S.V. Struktura khudozhestvennogo prostranstva v poezii V. Vysotskogo [The structure of artistic space in V. Vysotsky's poetry]. Available at: http://vysotskiy-lit.ru/ vysotskiy/kritika/sviridov-struktura-prostranstva/index.htm (Accessed 26 May 20I9). (In Russ.)

Sedov A.F. Dostoevskii i tekst (problema teksta s tochki zreniia poetiki povestvovaniia $v$ povestiakh i romanakh F.M. Dostoevskogo 60-70-kh godov) [Dostoevsky and the text (the problem of the text from the point of view of narrative poetics in the novels of F.M. Dostoevsky of the I860-70s)]. Balashov, 2002. Available at: https://refdb.ru/ look/2683III.html (Accessed 26 May 20I9). (In Russ.) universiteta Publ., 2009. I92p. (In Russ.) 